\title{
Vitrectomy and Internal
}

\author{
Yung-Jen Chen \\ Department of Ophthalmology, Chang Gung Memorial Hospital - Kaohsiung \\ Medical Center, Chang Gung University College of Medicine, Kaohsiung, \\ Taiwan, ROC
}

\section{Key Words}

Macular hole $\cdot$ Penetrating injury $\cdot$ Retinal folds $\cdot$ Traumatic macular hole

\begin{abstract}
An 8-year-old active boy suffered a penetrating injury to his right eye. A temporal retinal perforation with an adherent blood clot about 4-disc diameter from the fovea was noted. Six weeks after the initial primary repair, a macular hole $(\mathrm{MH})$ and retinal folds radiating from the penetrating site of the retina were found. Two months after the injury, the patient underwent a standard pars plana vitrectomy. Intraoperatively, the retinal folds still existed after creating a posterior hyaloid detachment and disappeared concurrently within the area of the internal limiting membrane peeling. Occlusion therapy was carried out after absorption of the intraocular gas. One year after the vitrectomy surgery, the $\mathrm{MH}$ remained closed with a visual acuity improving from 20/60 to 20/25 in his right eye. Our results suggest that vitrectomy with internal limiting membrane peeling and sequential occlusion therapy can achieve both anatomical and functional improvement in a child suffering a penetrating injury with a $\mathrm{MH}$ and retinal folds.
\end{abstract}

\section{Introduction}

Most traumatic macular holes (MH) result from closed-globe contusion injuries [1-4]. Patients with traumatic MH probably should be observed for 4-6 months rather than surgically repaired, which was advocated because of the possibility of spontaneous closure [5-9]. Vitrectomy surgery appears to be a highly successful surgical procedure to close $\mathrm{MH}$ and improve vision in eyes with traumatic $\mathrm{MH}[4,10]$.

In some cases, after removal of intraocular foreign body (IOFB), retinal folds radiating from the retinal impact sites may be noted $[11,12]$. We present a child with a penetrating

Dr. Yung-Jen Chen 
injury with a $\mathrm{MH}$ and retinal folds radiating from the retinal perforation site in which the patient had undergone vitrectomy surgery and internal limiting membrane (ILM) peeling.

\section{Case Report}

An 8-year-old active boy suffered a penetrating injury to his right eye by a sparkler when playing with his friends. He was immediately sent to our hospital, and an ocular examination revealed a small peripheral full-thickness corneal perforation, an inferior iris perforation associated with mind peripheral lens opacity, and vitreous hemorrhage. A temporal retinal perforation with an adherent blood clot about 4-disc diameter (DD) from the fovea was noted during immediate primary repair of the corneal perforation and prophylactic intravitreal antibiotics (vancomycin $1.0 \mathrm{mg}$, amikacin $0.4 \mathrm{mg}$, and dexamethasone $0.4 \mathrm{mg}$ ) injection. Six weeks after the initial surgery, a $\mathrm{MH}$ and retinal folds radiating from the penetrating site of the retina were noted by indirect ophthalmoscope and optical coherence tomography examination (fig. 1). The best corrected visual acuity was 20/60 in his right eye and 20/20 in the left eye, respectively.

The patient underwent a standard pars plana vitrectomy under general anesthesia about 2 months after the injury. The $\mathrm{MH}$ and retinal folds still existed during core vitrectomy. The remaining cortical vitreous was aspirated by active aspiration to create a posterior hyaloid detachment. After removal of the sheet-like posterior hyaloid membrane and the remaining cortical vitreous, $0.1 \mathrm{ml}$ of indocyanine green at a concentration of $2.5 \mathrm{mg} / \mathrm{ml}$ was injected in the temporal macular region without direct staining of the hole. The indocyanine green was immediately removed from the vitreous cavity with a vitreous cutter. A bent 25 -gauge needle was used to create a small temporal incision $2 \mathrm{DD}$ from the fovea. ILM peeling was then performed in the area around the macula (2 DD), and the eye was filled with a $16 \% \mathrm{C}_{3} \mathrm{~F}_{8}$ mixture. The retinal folds still existed after posterior hyaloid detachment and disappeared concurrently within the area of ILM peeling.

Before the vitrectomy surgery, the importance of a postoperative face-down position was explained to the patient and his mother who would attend him after the surgery. In order that the face-down position was maintained for 2 weeks, we kept encouraging and reminding them postoperatively. The patient revealed excellent compliance thanks to good family support. Occlusion therapy with the most accurate optical correction was carried out after absorption of the intraocular gas. The MH hole was closed within 2 weeks after the vitrectomy surgery and remained closed 1 year postoperatively with a best corrected visual acuity of 20/25 in the right eye (fig. 2). Continuous occlusion therapy was advised to the patient until the age of 10 .

\section{Discussion}

Eyeball trauma is one of the major causative factors of secondary MH. Most traumatic $\mathrm{MH}$ result from closed-globe contusion injuries [1-4]. However, their formation secondary to a penetrating or perforating injury has not been well documented in the literature. Blunt trauma causes acute anteroposterior compression of the globe, which leads to a lateral expansion of the equator area. This change may damage and tear the retina, resulting in a tear in the fovea [13]. Another theory proposed that a macular cyst caused by blunt trauma can develop into a $\mathrm{MH}$, as a macular cyst not seen immediately after trauma can later develop into a $\mathrm{MH}$ in the same eye [8]. In our case, no $\mathrm{MH}$ was noted immediately after the trauma and no vitreous traction or operculum was detected in the optical coherence tomography image. No spontaneous posterior hyaloid detachment was noted during the vitrectomy surgery. Therefore, the MH may be caused by a macular cyst or probable traction from the retinal folds. 
A spontaneous closure of the traumatic $\mathrm{MH}$ is not uncommon [7, 8]; the anatomical result after vitrectomy surgery is also favorable in comparison with idiopathic $\mathrm{MH}$ in aged people $[4,10]$. Traumatic MH should be observed for $4-6$ months rather than surgically repaired, which was advocated because of the possibility of a spontaneous closure [5-9]. In some cases of traumatic $\mathrm{MH}$, bridging of neuroretinal tissue, mimicking a foveal retinal detachment, and flattening of the foveal detachment with restoration of foveal depression could be noted during the spontaneous closure process [7, 9]. The patient's young age, the potentially high activity of the glial cell proliferation and the relatively small MH size might have been associated with the spontaneous closure process $[5,6,8$, 9]. In our case, we suspected that the MH would not have closed without surgery because the traction of the retinal folds might have prevented the closing of the $\mathrm{MH}$ and interfered with its healing process to a normal retinal appearance.

In open globe injury, proliferation along the vitreous gel in the wound site with membrane formation and contraction of these membranes results in traction and rhegmatogenous retinal detachment. Our case is more similar to cases with IOFB impacted or embedded in the retina rather than cases with severe open globe injury. In cases with IOFB, the retinal striae radiating from the retinal impacting sites with epiretinal membranes may be noted even after vitrectomy surgery [11, 12]. It is not possible to resolve the retinal folds by creating only a posterior vitreous detachment, but ILM peeling is also necessary [14]. In our case, the extensive retinal folds radiating from the impact site may be mainly due the traction of the ILM during the healing of the chorioretinal wound. In fact, the folds disappeared concurrently within the area of ILM peeling during surgery.

Postoperative face-down position is important in patients who have received vitrectomy and intraocular gas tamponade for closing the $\mathrm{MH}$. It is difficult for a child to maintain a face-down position postoperatively. The use of silicone oil is advocated in children who need long-term intraocular tamponade after a vitreoretinal surgery. However, additional surgery for silicone oil removal is necessary. In our case, the 8-yearold child revealed an excellent compliance with the face-down position thanks to good family support and our encouragement. Unilateral pediatric MHs may be amblyogenic; therefore, the timing of surgery should be based on the patient's age, duration of the hole, and potential for spontaneous closure [15]. In general, amblyopia does not recur after the age of 9 or 10 years. Occlusion therapy may also be beneficial for older children. We did not know if the spontaneous closure of MH would happen in our case. We attempted to close the MH with surgery and occlude the unaffected eye with the most accurate optical correction for this older child in whom the possibility of an amblyopia existed.

We presented a child with a penetrating injury with a $\mathrm{MH}$ and retinal folds radiating from the retinal perforation site. After vitrectomy surgery, including ILM peeling and sequential occlusion therapy, both anatomical and functional improvement were obtained.

\section{Disclosure Statement}

The author has no proprietary or commercial interest in any materials discussed in this article. 


\begin{tabular}{c|l|l|l}
$\begin{array}{c}\text { Case Reports in } \\
\text { Ophthalinology }\end{array}$ & $\begin{array}{l}\text { Case Rep Ophthalmol 2011;2:78-83 } \\
\text { DOI: 10.1159/000324909 }\end{array}$ & $\begin{array}{l}\text { Published online: } \\
\text { February 23, 2011 }\end{array}$ & $\begin{array}{l}\text { O 2011 S. Karger AG, Basel } \\
\text { ISSN 1663-2699 } \\
\text { www.karger.com/cop }\end{array}$ \\
\hline
\end{tabular}

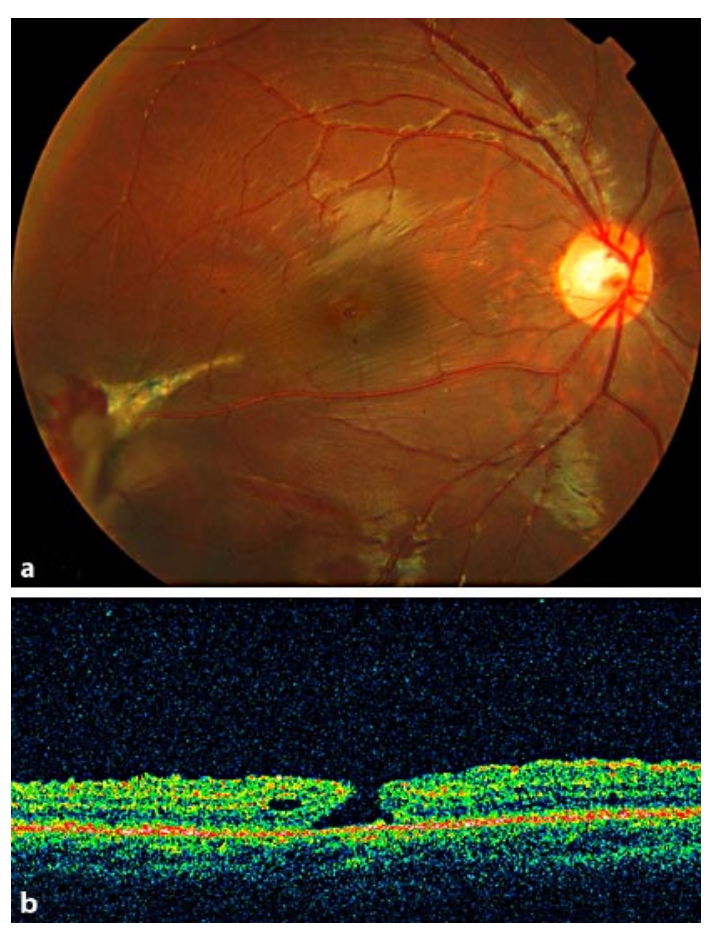

Fig. 1. Color photograph and optical coherence tomography (OCT) image of the right eye 6 weeks after the penetrating injury. a A MH and retinal folds radiating from the penetrating site were noted. b In the horizontal section of the OCT scan, a full-thickness $\mathrm{MH}$ associated with cystic changes was detected. The inner retinal surface is wrinkled and shows no epiretinal membranes. 


\begin{tabular}{c|l|l|l}
$\begin{array}{c}\text { Case Reports in } \\
\text { Ophthalinology }\end{array}$ & $\begin{array}{l}\text { Case Rep Ophthalmol 2011;2:78-83 } \\
\text { DOI: 10.1159/000324909 }\end{array}$ & $\begin{array}{l}\text { Published online: } \\
\text { February 23, 2011 }\end{array}$ & $\begin{array}{l}\text { O 2011 S. Karger AG, Basel } \\
\text { ISSN 1663-2699 } \\
\text { www.karger.com/cop }\end{array}$ \\
\hline
\end{tabular}
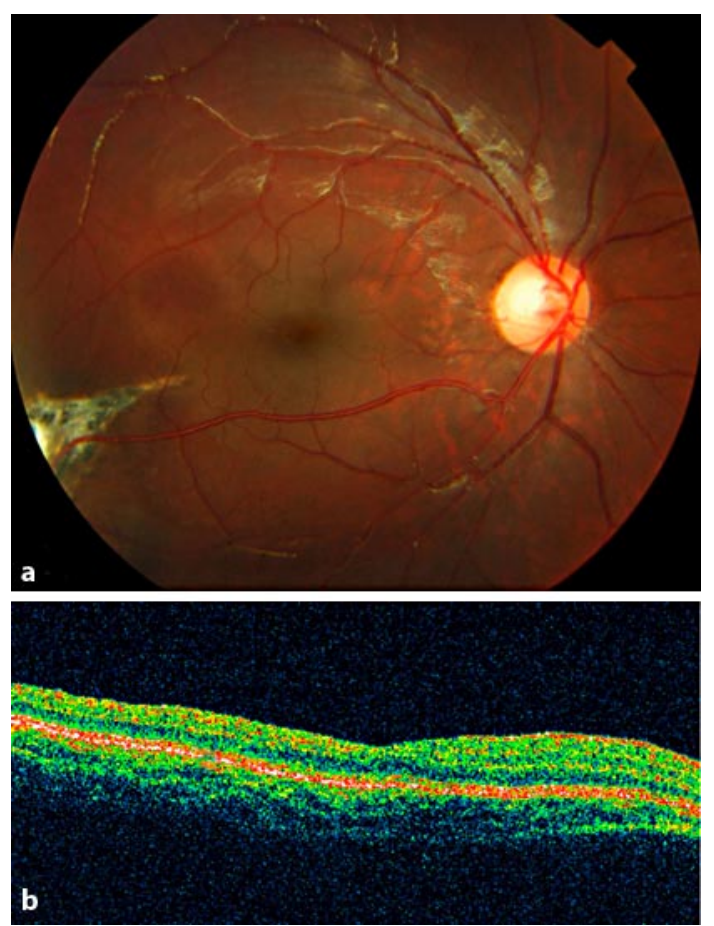

Fig. 2. Color photograph and OCT image of the right eye 6 months after vitrectomy. a The MH is closed and retinal folds have disappeared within the area of ILM peeling. $\mathbf{b}$ In the horizontal section of the OCT scan, the MH is closed and shows a smooth inner retinal surface. 


\section{References}

1 Rubin JS, Glaser BM, Thompson JT, Sjaarda RN, Pappas SS, Murphy RP: Vitrectomy, fluid-gas exchange and transforming growth factor-beta-2 for the treatment of traumatic macular holes. Ophthalmology 1995;102:1840-1845.

-2 Yanagiya N, Akiba J, Takahashi M, Shimizu A, Kakehashi A, Kado M, Hikichi T, Yoshida A: Clinical characteristics of traumatic macular holes. Jpn J Ophthalmol 1996;40:544-547.

-3 Amari F, Ogino N, Matsumura M, Negi A, Yoshimura N: Vitreous surgery for traumatic macular holes. Retina 1999;19:410-413.

-4 Johnson RN, McDonald HR, Lewis H, Grand MG, Murray TG, Mieler WF, Johnson MW, Boldt HC, Olsen KR, Tornambe PE, Folk JC: Traumatic macular hole: observations, pathogenesis, and result of vitrectomy surgery. Ophthalmology 2001:108:853-857.

5 Kusaka S, Fujikado T, Ikeda T, Tano Y: Spontaneous disappearance of traumatic macular holes in young patients. Am J Ophthalmol 1997;123:837-839.

6 Parmar DN, Stanga PE, Reck AC, Vingerling JR, Sullivan P: Imaging of a traumatic macular hole with spontaneous closure. Retina 1999;19:470-472.

7 Mitamura Y, Saito W, Ishida M, Yamamoto S, Takeuchi S: Spontaneous closure of traumatic macular hole. Retina 2001;21:385-389.

$\checkmark 8$ Yamada H, Sakai A, Yamada E, Nishimura T, Matsumura M: Spontaneous closure of traumatic macular hole. Am J Ophthalmol 2002;134:340-347.

9 Menchini U, Virgili G, Giacomelli G, Cappelli S, Giansanti F: Mechanism of spontaneous closure of traumatic macular hole: OCT study of one case. Retina 2003;23:104-106.

10 Garcia-Arumi J, Corcostegui B, Cavero L, Sararols L: The role of vitreoretinal surgery in the treatment of posttraumatic macular hole. Retina 1997;17:372-377.

11 Slusher MM: Intraretinal foreign bodies: management and observations. Retina 1990;10(suppl):S50-S54.

- 12 Lai WW, Meyers SM, Brent GJ, Humayan M, Langston RH: Management of the retinal impact site after intraocular foreign body trauma. Ophthalmology 2000;107:811-812.

13 Delori F, Pomerantzeff O, Cox MS: Deformation of the globe under high-speed impact: Its relation to contusion injuries. Invest Ophthalmol 1969;8:290-301.

- 14 Ikeda T, Sato K, Otani H, Yu S, Ikeda N, Mimura O: Vitreous surgery combined with internal limiting membrane peeling for traumatic macular hole with severe retinal folds. Acta Ophthalmol Scand 2002;80:88-90.

15 Gill MK, Lou PL: Traumatic macular holes. Int Ophthalmol Clin 2002;42:97-106. 